\title{
Pemanfaatan Limbah Tempurung Kelapa Muda sebagai Alternatif Material Akustik
}

\author{
Susilo Indrawati* dan Suyatno \\ Departemen Fisika- FMIPA, Institut Teknologi Sepuluh Nopember Kampus ITS Sukolilo, Surabaya, 60111
}

\begin{abstract}
Intisari
Penelitian ini merupakan studi awal untuk meneliti tempurung kelapa khususnya tempurung kelapa muda, karena merupakan limbah yang jarang dimanfaatkan. Tempurung kelapa muda di keringkan dan dipisahkan dari serabutnya, kemudian dibentuk berupa setengah lingkaran dan disusun menjadi panel akustik. Panel akustik tersebut terdiri dari susunan setengah lingkaran dengan diameter $10 \mathrm{~cm}$ yang disusun secara cembung, cekung, cembung dengan pemberian lubang, dan cembung pemberian lubang dengan diisi bahan absorber. Pengujian dilakukan dengan mengacu pada ISO 354, pengujian ini terdiri dari penentuan nilai koefisien absorbsi bahan, pola hamburan panel, dan penentuan nilai koefisien hamburan. Tujuan dari penelitian ini selain resonator memiliki nilai estetika mata juga akan memiliki nilai lebih dalam akustik ruang. Akustik ruang yang dimaksud adalah suatu ruang yang memerlukan treatment khusus dalam akustik misalnya ruang studio music, broadcast, tempat ibadah, home taeter, ruang music, dan lain-lain. Dari hasil pengukuran dan perhitungan diperoleh nilai koefisien absorbsi $(\alpha)$ yang cukup signifikan pada frekuensi $1000 \mathrm{~Hz}$. Untuk panel akustik berupa susunan tempurung cembung memiliki nilai $\alpha=0,7$, sedangkan tempurung yang terdiri dari susunan cekung memiliki $\alpha=0,03$. Penambahan panel tempurung kelapa muda yang disusun secara cembung dan cekung dapat menurunkan nilai SPL di atas frekuensi $1500 \mathrm{~Hz}$ dan penurunannya sama antara tempurung yang disusun secara cembung dan cekung. Pemberian lubang pada tempurug yang disusun secara cembung menurunkan nilai SPL pada frekuensi $1000 \mathrm{~Hz}$. Sehingga dapat disimpulkan bahwa pemberian porosi/ lubang pada tempurung yang disusun cembung dan diisi ampas tebu mampu mengurangi SPL pada frekuensi di atas $1000 \mathrm{~Hz}$.
\end{abstract}

\begin{abstract}
This research will utilize coco shell as an acoustic tile, specifically resonator so that a coco shell has a better value. Coco shell used will be a young coco shell, since it is a rarely utilized waste. The resonator will be tested in regard of its ability to absorb and scatter sound. This research consists of a test to determine the value of the absorption coefficient of the material, the scattering pattern panel, and the determination coefficient scattering. The purpose of this research in addition resonator has aesthetic value currency will also have more value in the acoustic space. Acoustic room means a room that requires special treatment in acoustic music studio room, for example, broadcast, places of worship, home theatre, music chamber, and others. The absorption coefficient for convex shell has greater value than the concaves, especially at a frequency of $1000 \mathrm{~Hz}$ and $4000 \mathrm{~Hz}$. Perforate addition in the convex shell makes the scattering pattern smoother. The addition of sugar cane pulp has the same scattering pattern. The scattering coefficient has a negative values exception at a frequency of $500 \mathrm{~Hz}$, especially for acoustic panels are arranged in convex and convex panels that filled by bagasse. When the measurement in an anechoic chamber, the result says that panels made from young coconut shell either arranged convex and concave above can reduce the frequency of $1500 \mathrm{~Hz}$. there is perforation/hole on the composition of convex shell panels capable of lowering the level of pressure above $1000 \mathrm{~Hz}$.
\end{abstract}

KATA KUNCI: coconut shell, resonator, room acoustics, ISO 354

http://dx.doi.org/10.12962/j24604682.v13i3.2842

\section{PENDAHULUAN}

Indonesia merupakan salah satu negara yang memiliki luas lahan pohon kelapa terbesar di Dunia. Namun hal yang disayangkan adalah Indonesia tidak mampu mengangkat perekonomian kesejahteraan petani kelapa. Berbeda dengan Negara Filipina yang hanya memiliki luas lahan jauh di bawah Indonesia ternyata mampu memperoleh keuntungan devisa yang lebih besar dibanding Indonesia. Keberhasilan Filipina

*E-MAIL: susilo.indra.its@gmail.com meraup devisa yang fantastik karena berhasil mendiversikan buah kelapa menjadi banyak produk olahan.

Produk olahan tempurung kelapa ditangan pengrajin, dapat diubah menjadi barang yang memiliki nilai estetika dan nilai tambah sendiri. Produk yang dihasilkan meliputi tas, meja lampu, hiasan dll. Dengan seiringnya waktu tempurung kelapa sudah lebih memiliki nilai tambah dengan di ubah menjadi mozaik coconut dan harganya mencapai US\$ 65 atau setara dengan Rp 845.000 per meter persegi. Namun dalam hal ini mozaik coconut hanya dilihat dari segi estetika mata saja (sebagai hiasan).

Salam (2015) membuat panel acoustic diffuser wall yang terbuat dari tempurung kelapa [1]. Sama halnya dengan 
mozaik coconut penelitian tersebut tidak dilakukan penelitian lanjutan, yang berhubungan dengan kemampuannya menghamburkan bunyi. Sehingga fungsi dari acoustic diffuser wall tersebut hanya sebagai hiasan bukan sebagai panel akustik yang mampu memecahkan permasalahan akustik pada ruang akustik yang sesuai fungsinya.

Dalam penelitian ini akan dibuat suatu panel akustik tile berupa resonator yang terbuat dari tempurung kelapa muda. Tempurung kelapa muda yang dipilih karena jarang dimanfaatkan dan menjadi limbah. Kelapa muda akan dipilih berdasarkan ukuran, nantinya akan dilakukan diberi perlakuan dan di desain menjadi resonator yang dimanfaatkan untuk akustik performance. Panel akustik tersebut terdiri dari susunan setengah lingkaran dengan diameter $10 \mathrm{~cm}$ yang disusun secara cembung, cekung, cembung dengan pemberian lubang, dan cembung pemberian lubang dengan diisi bahan tebu. Resonator yang di buat selain memiliki kemampuan dalam menghamburkan bunyi juga mampu mengabsorpsi bunyi pada frekuensi tertentu. Putra (2012) menyebutkan bahwaampas tebu memiliki kemampuan mengabsorbsi bunyi sebesar 0,65 pada frekuensi $1,2-4,5 \mathrm{kHz}$ [2]. Sehingga diharapkan resonator yang terbuat dari limbah tempurung kelapa selain memiliki nilai estetika juga mampu digunakan untuk akustik ruang.

\section{METODOLOGI PENELITIAN}

\section{Pengukuran koefisien absorbsi $(\alpha)$}

Pengukuran koefisien absorbsi menggunakan metode ruang dengung yang mengacu pada ISO 354 [3]. Ruang dengung dirancang dengan geometri yang tidak beraturan, setiap sisi dindingnya dibuat tidak saling berhadapan, untuk menghindari terjadinya standing wave. Persamaan yang digunakan untuk menentukan koefisien absorbsi adalah persamaan Sabine. Rumusan yang akan digunakan adalah:

$$
\alpha=0,16 \frac{V}{A}\left(\frac{1}{T_{2}}-\frac{1}{T_{1}}\right)
$$

dengan $\alpha$ adalah koefisien penyerapan difuser, $\mathrm{V}$ adalah volume ruang dengung $\left(\mathrm{m}^{3}\right)$, A adalah luas bahan uji $\left(\mathrm{m}^{2}\right), \mathrm{T}_{1}$ adalah waktu dengung ruang uji saat tidak ada bahan uji (sekon), $\mathrm{T}_{2}$ adalah waktu dengung ruang uji saat ada bahan uji (sekon).

Parameter yang perlu diukur adalah waktu dengung sebelum dan setelah penambahan bahan di ruang dengung. Pengukuran waktu dengung dalam penelitian ini sedapat mungkin akan mengikuti standart Acoustics-Measurement of sound Absorption in a Reverberation Room, International Standart, ISO 354-1985. Karena sarana ruang dengung yang disyaratkan standart ISO 354 itu tidak ada di ITS, maka banyak langkah Carlisle dan Hooker (2004) [4] yang akan diikuti/diadopsi dalam penelitian ini. Pengukuran waktu dengung yang dilakukan ini untuk menentukan nilai koefisien absorbs bunyi. Pengujian ini dilakukan di ruang reverberation yang ada di Laboratorium instrumentasi fisika bangunan yang

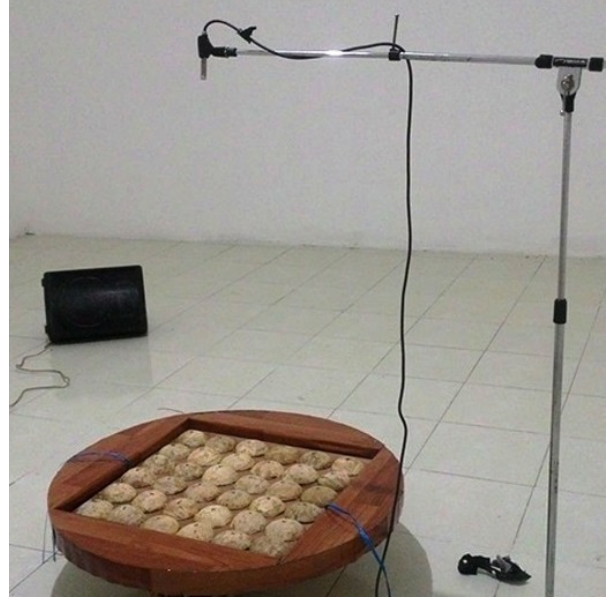

Gambar 1: Pengukuran waktu dengung [5].

ada di jurusan Fisika FMIPA ITS. Ruang uji ini memiliki volume $140,058 \mathrm{~m}^{3}$. Adapun rancangan pengukuran dapat dilihat pada Gambar 1 [5].

\section{Pengukuran koefisien hamburan (s)}

Metode pengukuran koefisien hamburan didasarkan pada ISO 354 yakni pengukuran penyerapan bunyi dalam ruang dengung. ISO yang saat ini digunakan untuk mengukur koefisien hamburan yakni ISO17497-1 merupakan perluasan dari ISO 354 meliputi kondisi pengukuran yang berkaitan dengan bahan uji berupa lingkaran yang berputar. Koefisien hamburan dapat dihitung dari koefisien penyerapan difuser $(\alpha)$ dan koefisien penyerapan spekular $\left(\alpha_{\text {spec }}\right)[6]$.

$$
\begin{aligned}
s & =\frac{\alpha_{\text {spec }}-\alpha}{1-\alpha} \\
\alpha_{\text {spec }} & =0,16 \frac{V}{A}\left(\frac{1}{T_{4}}-\frac{1}{T_{3}}\right)
\end{aligned}
$$

dengan $\alpha$ adalah koefisien penyerapan difuser, $\alpha_{\text {spec }}$ adalah koefisien penyerapan spekular, $\mathrm{T}_{3}$ adalah waktu dengung ruang uji saat bahan uji ada dan meja putar tidak berputar (sekon), $\mathrm{T}_{4}$ adalah waktu dengung ruang uji saat bahan uji ada dan meja putar berputar (sekon).

Bahan uji diletakkan pada meja putar dan dilakukan pengukuran dengan sudut datang yang berbeda-beda. Dalam metode ISO, bahan uji harus diletakkan pada meja putar dalam sebuah ruang dengung, dapat dilihat pada Gambar 2 . Data yang diperoleh adalah data waktu dengung ketika bahan uji ada di ruang dengung dengan dan tanpa meja berputar.

\section{HASIL DAN PEMBAHASAN}

\section{Koefisien absorbsi $(\alpha)$}

Pengukuran ini menggunakan metode ruang dengung standart ISO 354-1985 menggunakan Pers.(1) sehingga data yang diperlukan berupa waktu dengung. Waktu dengung yang 


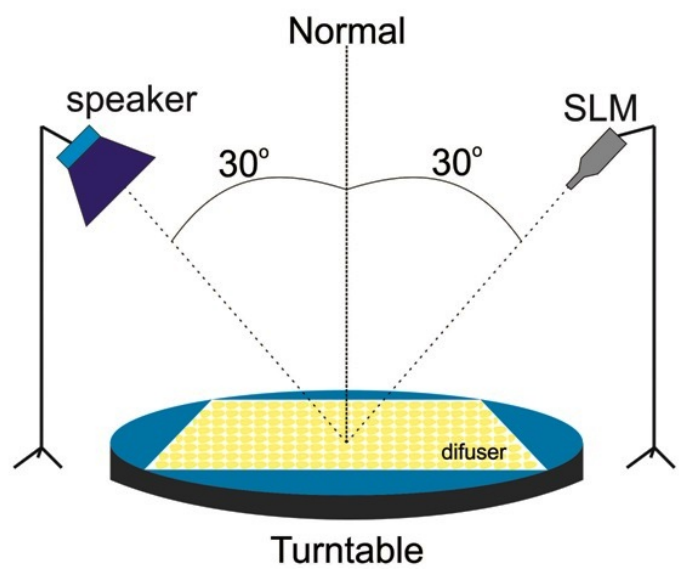

Gambar 2: Pengukuran penentuan koefisien hamburan.

TABEL I: Koefisien absorbsi $(\alpha)$ [5].

\begin{tabular}{ccc}
\hline $\begin{array}{c}\text { Frekuensi } \\
(\mathrm{Hz})\end{array}$ & $\begin{array}{c}\text { Nilai koefisien absorbsi }(\alpha) \\
\text { Tempurung cembung }\end{array}$ \\
\hline 125 & 0.06 & 0.02 \\
250 & 0.10 & 0.13 \\
500 & 0.28 & 0.23 \\
1000 & 0.70 & 0.03 \\
2000 & 0.11 & 0.12 \\
4000 & 0.21 & 0.06 \\
\hline
\end{tabular}

diukur adalah waktu dengung ketika belum ada bahan dan waktu dengung setelah ada bahan yang dimasukkan ke dalam ruang uji. Data waktu dengung yang diperoleh kemudian dengan menggunakan Pers.(1) diperoleh data koefisien absorbsi seperti ditunjukkan pada Tabel I.

Dapat dilihat dalam Tabel I bahwa data yang dihasilkan nilai koefisien absorbsi untuk tempurung cembung dan cekung memiliki perbedaan yang cukup signifikan pada frekuensi $1000 \mathrm{~Hz}$. Untuk panel yang menggunakan tempurung cembung diperoleh nilai 0,70 hal ini berarti bahwa kemampuannya mengabsorbsi pada frekuensi $1000 \mathrm{~Hz}$ adalah $70 \%$. Hal ini sangat berbeda sekali ketika panel akustik berupa tempurung cekung yang hanya memiliki kemampuan $3 \%$. Sehinggga dapat disimpulkan bahwa apabila suatu ruang memiliki permasalahan khususya pada frekuensi $1000 \mathrm{~Hz}$, misalnya ingin mengabsorbsi energi yang datang pada frekuensi 1000 $\mathrm{Hz}$ maka bisa digunakan panel akustik berupa tempurung dengan susunan cembung.

\section{Koefisien hamburan (s)}

Sama halnya dengan pengambilan koefisien absorbsi $(\alpha)$, pengambilan data koefisien hamburan (s) juga dilakukan di ruang Reverberation di Laboratorium Instrumentasi Akustik Jurusan Fisika ITS. Difuser yang dibuat berukuran 0,6 × 0,6 $\mathrm{m}^{2}$ menyesuaikan dengan ukuran panel diffuser serta mengacu pada metode yang dilakukan sebelumnya oleh F.-M. Lin(2010) [7]. Pengukuran koefisien hamburan menggunakan tiga variasi yaitu tempurung cembung, tempurung cekung dan tempurung berlubang. Data hasil pengukuran waktu dengung
TABEL II: Koefisien hamburan.

\begin{tabular}{cccc}
\hline \hline $\begin{array}{c}\text { Frekuensi } \\
(\mathrm{Hz})\end{array}$ & $\begin{array}{c}\text { N i l a i } \\
\text { Tempurung } \\
\text { cembung }\end{array}$ & $\begin{array}{c}\text { K o e f i s i e npurung } \\
\text { cekung }\end{array}$ & $\begin{array}{c}\text { s c a t e r i n g } \\
\text { Tempurung } \\
\text { cembung Berlubang }\end{array}$ \\
\hline 125 & -2.688 & 1.999 & -8.021 \\
250 & 5.454 & 2.599 & 14.703 \\
500 & 0.266 & -0.296 & 0.936 \\
1000 & 2.156 & -6.705 & 1.448 \\
2000 & -1.909 & 7.751 & 2.357 \\
4000 & -2.226 & -2.942 & -2.521 \\
8000 & 3.090 & 13.855 & 2.652 \\
\hline \hline
\end{tabular}

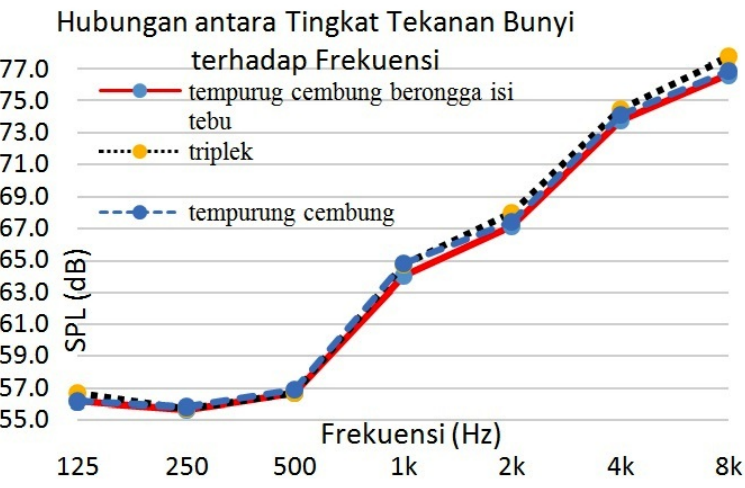

Gambar 3: Grafik Hubungan antara SPL terhadap frekuensi.

dengan menggunakan Pers.(1), (2) dan (3) sehingga diperoleh nilai koefisien hamburan seperti ditunjukkan pada Tabel II.

Dari hasil tersebut diperoleh hanya pada data frekuensi $500 \mathrm{~Hz}$ pada tempurung cembung dan tempurung cembung berlubang yang memiliki nilai koefisien hamburan nilai antara $0-1$. Untuk lebih mengetahui peranan dari difuser tempurung kelapa disini juga perlu dilakukan pengukuran terhadap resonansi yang dihasilkan oleh difuser tersebut. Pengukuran mengenai efek resonansi dilakukan di ruang anechoic (ruang bebas pantul). Data yang dilakukan pada pengukuran ini terdiri dari tiga variasi yaitu tempurung cembung, triplek dan tempurung cembung berongga yang di isi oleh ampas tebu. Dari hasil pengukuran tersebut diperoleh data yang ditampilkan dalam Gambar 3.

Dalam Gambar 3 terlihat bahwa dari grafik ke tiga bahan memiliki karakteristik yang hampir sama pada semua frekuensi. Penambahan panel tempurung kelapa muda yang disusun secara cembung dan cekung dapat menurunkan nilai SPL di atas frekuensi $1500 \mathrm{~Hz}$ dan penurunannya sama antara tempurung yang disusun secara cembung dan cekung. Pemberian lubang pada tempurug yang disusun secara cembung menurunkan nilai SPL pada frekuensi $1000 \mathrm{~Hz}$. Sehingga dapat disimpulkan bahwa pemberian porosi/ lubang pada tempurung yang disusun cembung dan diisi ampas tebu mampu mengurangi SPL pada frekuensi di atas $1000 \mathrm{~Hz}$. 


\section{SIMPULAN}

Berdasarkan hasil penelitian diperoleh simpulan bahwa pemberian porosi (lubang) pada tempurung cembung mengakibatkan pola hamburan yang lebih merata. Penambahan ampas tebu menyebabkan pola hamburan yang sama hanya SPL berkurang amplitudo dan besarya nilai koefisien hambu- ran bernilai negatif, terkecuali pada frekuensi $500 \mathrm{~Hz}$.

\section{Ucapan Terima Kasih}

Penelitian ini didanai oleh proyek penelitian PNBP-ITS No: 31111/IT2.11/PN.08/2016.
[1] N. salam, How to make panel Acoustic Diffuser wall pemanfaatan limbah tempurung kelapa menjadi panel acoustic diffuser wall dinding, (2015): 1080plus/How-Acoustic-Diffuserwall/u9f94PE712w.video.

[2] A. Putra, et al., Procedia Engineering, 53, 632-638 (2013).

[3] International Standard ISO 354, Acoustics Measurement of sound absorption in reverberation room, Second edition, Switzerland, 2003

[4] E.J. Carlisle, R.I. Hooker, Small chamber reverberant absorption Measurement, Proceedings of Acoustics, Conference of the
Australian Acoustical Society, Australia, 2004.

[5] S. Indrawati, Suyatno, CRS (Coco Shell Resonator) Unique design resonator from coco shell waste for Acoustic performance, in Engineering Physics International Conference, EPIC 2016, ITB, Bandung, 2016.

[6] T.J. Cox, Acoustic absorbers and diffusers: theory, design and application (second edition Spoon Press, London, 2004).

[7] F.-M. Lin, P.Y. Hong, C.-Y. Lee, Applied Acoustics, 71(1), 68-78 (2010). 